www.nature.com/ja

\title{
Xanthoradones, new potentiators of imipenem activity against methicillin-resistant Staphylococcus aureus, produced by Penicillium radicum FKI-3765-2 II. Structure elucidation
}

\author{
Hiroyuki Yamazaki ${ }^{1}$, Satoshi Ōmura ${ }^{2}$ and Hiroshi Tomoda ${ }^{1}$ \\ The structures of xanthoradones A and B, new potentiators of imipenem activity against methicillin-resistant Staphylococcus \\ aureus produced by Penicillium radicum FKI-3765-2, were elucidated by spectroscopic studies, including various NMR \\ experiments. These compounds have an asymmetric biaryl skeleton, which contains dihydronaphthopyranone and \\ naphthoquinone moieties.
}

The Journal of Antibiotics (2009) 62, 435-437; doi:10.1038/ja.2009.61; published online 17 July 2009

Keywords: fungal metabolites; imipenem potentiator; methicillin-resistant Staphylococcus aureus (MRSA); structure elucidation; xanthoradone; xanthoviridicatin

\section{INTRODUCTION}

Two new compounds, designated xanthoradones A and B (Figure 1), were isolated as potentiators of imipenem activity against methicillinresistant Staphylococcus aureus from the culture broth of Penicillium radicum strain FKI-3765-2. ${ }^{1}$ The taxonomy of the producing strain, fermentation, isolation and biological properties of the xanthoradones were described in a previous paper. ${ }^{1}$ In this study, the physicochemical properties and structure elucidation of xanthoradones are described.

\section{RESULTS}

Physico-chemical properties

The physico-chemical properties of xanthoradones $\mathrm{A}$ and $\mathrm{B}$ are summarized in Table 1. They had similar UV spectra with absorption maxima at $218 \mathrm{~nm}, 263-267 \mathrm{~nm}$ and $373-375 \mathrm{~nm}$. The IR absorption at $1606-1778 \mathrm{~cm}^{-1}$ and $3403-3407 \mathrm{~cm}^{-1}$ suggested the presence of carbonyl and hydroxyl groups in their structures. These data indicated that they share the same skeleton.

\section{Structure elucidation of xanthoradone A}

The molecular formula of xanthoradone A was determined to be $\mathrm{C}_{27} \mathrm{H}_{22} \mathrm{O}_{9}$ on the basis of high-resolution electrospray ionization timeof-flight mass spectrum (HRESI-TOF-MS) measurement. The ${ }^{13} \mathrm{C}$ NMR spectrum (in $\mathrm{CDCl}_{3}$ ) showed 27 resolved signals, which were classified into two methyl carbons, one methylene carbon, four $\mathrm{sp}^{2}$ methine carbons, two oxygenated methyl carbons, one oxygenated methine carbon, nine $\mathrm{sp}^{2}$ quaternary carbons, five oxygenated $\mathrm{sp}^{2}$ quaternary carbons and three carbonyl carbons by analyzing the DEPT and heteronuclear single quantum coherence (HSQC) spectra. The ${ }^{1} \mathrm{H}$ NMR spectrum (in $\mathrm{CDCl}_{3}$ ) displayed 22 proton signals, nine of which were suggested to be three hydroxy protons $(\delta 9.73,12.5$ and 13.9) and two oxygenated methyl protons ( $\delta 3.84$ and 3.92 ), as reported for xanthoviridicatin $\mathrm{F}^{2}$ These results supported the molecular formula. The connectivity of proton and carbon atoms was established by the ${ }^{13} \mathrm{C}-{ }^{1} \mathrm{H}$ HSQC spectrum (Table 2). Analyses of ${ }^{1} \mathrm{H}-{ }^{1} \mathrm{H}$ COSY revealed the presence of the partial structure I, as shown in Figure 2a. Furthermore, ${ }^{13} \mathrm{C}-{ }^{1} \mathrm{H}$ long-range couplings of ${ }^{2} \mathrm{~J}$ and ${ }^{3} \mathrm{~J}$ observed in the ${ }^{13} \mathrm{C}-{ }^{1} \mathrm{H}$ heteronuclear multiple bond coherence (HMBC) spectrum gave the following linkages (Figure $2 \mathrm{~b}$ ): (1) Cross peaks from $\mathrm{H}_{2}-3(\delta 3.00,3.06)$ to $\mathrm{C}-4(\delta 133.5), \mathrm{C}-5(\delta 116.1)$ and C-13 ( $\left.\delta 99.7\right)$; from H-5 ( $\delta 6.99)$ to C-3 ( $\delta 34.7), \mathrm{C}-6$ ( $\delta 140.0), \mathrm{C}-7$ ( $\delta 98.1), \mathrm{C}-11(\delta$ $108.4)$ and $\mathrm{C}-13$; from $\mathrm{H}-7(\delta$ 6.71) to C-5, C-8 $(\delta$ 160.3), C-9 $(\delta$ $109.0)$ and $\mathrm{C}-11$; from $\mathrm{OH}-10(\delta 9.73)$ to $\mathrm{C}-9, \mathrm{C}-10(\delta 154.7)$ and $\mathrm{C}-$ 11; from $\mathrm{OH}-12(\delta 13.9)$ to $\mathrm{C}-11, \mathrm{C}-12(\delta 162.7)$ and $\mathrm{C}-13$; and from $\mathrm{H}_{3}-15$ ( $\left.\delta 3.84\right)$ to $\mathrm{C}-8$ indicated that a naphthalene skeleton connects the partial structure I at C-4. Furthermore, the findings that the chemical shift of C-2 $(\delta 76.8)$ corresponds to that of an oxygenated carbon and that the $\mathrm{OH}-12$ proton $(\delta$ 13.9) shifted to a lower field because of hydrogen bonding indicated that $\mathrm{C}-2$ and $\mathrm{C}-13$ are connected through an ester bond. This connection was supported by the chemical shift of $\mathrm{C}-1(\delta$ 171.5) corresponding to an ester bond and the long-range coupling of ${ }^{4} \mathrm{~J}$ observed from $\mathrm{H}-5$ to C-1 in ${ }^{13} \mathrm{C}-{ }^{1} \mathrm{H}$ HMBC (Figure 2). Thus, these data indicated that xanthoradone A was found to have a dihydronaphthopyranone skeleton. (2)

${ }^{1}$ Graduate School of Pharmaceutical Sciences, Kitasato University, Tokyo, Japan and ${ }^{2}$ Kitasato Institute for Life Sciences, Kitasato University, Tokyo, Japan Correspondence: Professor H Tomoda, Graduate School of Pharmaceutical Sciences, Kitasato University, 5-9-1 Shirokane, Minato-ku, Tokyo 108-8641, Japan. E-mail: tomodah@pharm.kitasato-u.ac.jp

Received 16 April 2009; revised 29 May 2009; accepted 25 June 2009; published online 17 July 2009 
<smiles>[R7]C1=CC(=O)c2c(cc([R])c(-c3c(OC)cc4cc5c(c(O)c4c3O)C(=O)O[C@H](C)C5)c2O)C1=O</smiles>

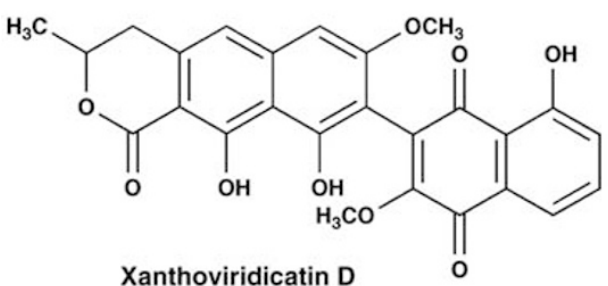<smiles>[R2]C1=C(c2c(OC)cc3cc4cc(C)oc(=O)c4c(O)c3c2O)C(=O)c2c(O)cc(Br)cc2C1=O</smiles>

\begin{tabular}{ccc}
\hline Xanthoviridicatin & $\mathbf{R}_{1}$ & $\mathbf{R}_{2}$ \\
\hline E & $-\mathrm{CH}_{3}$ & $-\mathrm{OCH}_{3}$ \\
F & $-\mathrm{OCH}_{3}$ & $-\mathrm{CH}_{3}$
\end{tabular}

Figure 1 Structures of xanthoradones A, B and xanthoviridicatins D to F.

Table 1 Physico-chemical properties of xanthoradones A and B

\begin{tabular}{lll}
\hline & Xanthoradone $A$ & Xanthoradone $B$ \\
\hline Appearance & Orange crystal & Orange crystal \\
Molecular weight & 490 & 490 \\
Molecular formula & $\mathrm{C}_{27} \mathrm{H}_{22} \mathrm{O}_{9}$ & $\mathrm{C}_{27} \mathrm{H}_{22} \mathrm{O}_{9}$ \\
& & \\
HRESI-TOF-MS (m/z) & & \\
$\quad$ Calculated & $489.1186(\mathrm{M}-\mathrm{H})^{-}$ & $489.1186(\mathrm{M}-\mathrm{H})^{-}$ \\
$\quad$ Found & $489.1136(\mathrm{M}-\mathrm{H})^{-}$ & $489.1149(\mathrm{M}-\mathrm{H})^{-}$ \\
$\mathrm{UV}(\mathrm{MeOH}), \lambda_{\max }$ & $218(32600), 263$ & $218(55300), 267$ \\
$\mathrm{~nm}(\varepsilon)$ & $(53400), 375(15100)$ & $(34700), 373(13000)$ \\
{$[\alpha]_{D}^{26}$} & $+320.1^{\circ}\left(c=0.1, \mathrm{CHCl}_{3}\right)$ & $+167.9^{\circ}\left(\mathrm{c}=0.1, \mathrm{CHCl}_{3}\right)$ \\
$\mathrm{IR}(\mathrm{KBr}), v_{\max }\left(\mathrm{cm}^{-1}\right)$ & $3407,2971,1778,1681$, & $3403,2967,1641,1606$, \\
& 1631,1598 & 1579,1542 \\
\hline
\end{tabular}

Cross peaks from $\mathrm{H}-2^{\prime}\left(\delta\right.$ 6.08) to C-1' $(\delta 190.6), \mathrm{C}-3^{\prime}(\delta$ 160.9), C-4' $\left(\delta\right.$ 179.8) and C-10' $\left(\delta\right.$ 112.0); from H-6 $\left(\delta\right.$ 7.67) to C-4 ${ }^{\prime}, \mathrm{C}-5^{\prime}(\delta$ $129.8), C^{\prime} 7^{\prime}(\delta 147.2), \mathrm{C}-8^{\prime}(\delta 130.6), \mathrm{C}-10^{\prime}$ and C-12' $(\delta 20.5)$; from

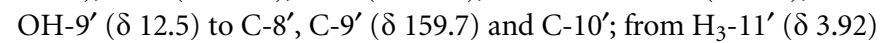
to $\mathrm{C}-3^{\prime}$; and from $\mathrm{H}_{3}-12^{\prime}(\delta 2.21)$ to $\mathrm{C}-6^{\prime}$ ( $\delta$ 121.3), C-7' and C-8 indicated that xanthoradone $\mathrm{A}$ has another naphthoquinone skeleton. This was supported by the chemical shifts of two carbonyl carbons $\left(\mathrm{C}-1^{\prime}(\delta\right.$ 190.6) and C-4' $(\delta 179.8))$ derived from a quinone skeleton and the UV absorption $(263 \mathrm{~nm})$. Finally, the correlations observed between $\mathrm{H}_{3}-15$ and $\mathrm{OH}-9^{\prime}$, and between $\mathrm{OH}-10$ and $\mathrm{H}_{3}-12^{\prime}$ in
Table $2{ }^{1} \mathrm{H}$ - and ${ }^{13} \mathrm{C}$ NMR chemical shifts of xanthoradones $\mathrm{A}$ and $\mathrm{B}$

\begin{tabular}{|c|c|c|c|c|}
\hline \multirow[b]{2}{*}{ Position } & \multicolumn{2}{|c|}{ Xanthoradone A } & \multicolumn{2}{|c|}{ Xanthoradone B } \\
\hline & $\delta_{c}$ & $\delta_{H}$ & $\delta_{c}$ & $\delta_{H}$ \\
\hline 1 & 171.5 & - & 171.5 & - \\
\hline 2 & 76.8 & $4.79 m$ & 76.6 & $4.75 \mathrm{~m}$ \\
\hline 3 & 34.7 & $\begin{array}{c}\text { ax: } 3.00 \mathrm{dd} \\
(J=17.0,10.0 \mathrm{~Hz}) \\
\text { eq: } 3.06 \mathrm{dd} \\
(J=17.0,4.0 \mathrm{~Hz})\end{array}$ & 34.7 & $\begin{array}{c}\text { ax: } 2.98 \mathrm{dd} \\
(J=17.0,10.0 \mathrm{~Hz}) \\
\text { eq: } 3.05 \mathrm{dd} \\
(J=17.0,4.0 \mathrm{~Hz})\end{array}$ \\
\hline 4 & 133.5 & - & 133.3 & - \\
\hline 5 & 116.1 & $6.99 \mathrm{~s}$ & 116.1 & $6.94 \mathrm{~s}$ \\
\hline 6 & 140.0 & - & 140.3 & - \\
\hline 7 & 98.1 & $6.71 \mathrm{~s}$ & 98.1 & $6.67 \mathrm{~s}$ \\
\hline 8 & 160.3 & - & 160.8 & - \\
\hline 9 & 109.0 & - & 106.4 & - \\
\hline 10 & 154.7 & - & 155.2 & - \\
\hline $10-\mathrm{OH}$ & & $9.73 \mathrm{~s}$ & & $9.69 \mathrm{~s}$ \\
\hline 11 & 108.4 & & 108.4 & - \\
\hline 12 & 162.7 & - & 162.8 & - \\
\hline $12-\mathrm{OH}$ & & $13.9 \mathrm{~s}$ & & $13.8 \mathrm{~s}$ \\
\hline 13 & 99.7 & - & 99.5 & - \\
\hline 14 & 20.7 & $1.57 \mathrm{~d}(J=7.0 \mathrm{~Hz})$ & 20.7 & $1.53 \mathrm{~d}(\mathrm{~J}=7.0 \mathrm{~Hz})$ \\
\hline 15 & 56.0 & $3.84 \mathrm{~s}$ & 56 & $3.82 \mathrm{~s}$ \\
\hline $1^{\prime}$ & 190.6 & - & 189.0 & - \\
\hline $2^{\prime}$ & 109.6 & $6.08 \mathrm{~s}$ & 135.8 & $6.73 q(J=2.0 \mathrm{~Hz})$ \\
\hline $3^{\prime}$ & 160.9 & - & 148.3 & - \\
\hline $4^{\prime}$ & 179.8 & - & 185.0 & - \\
\hline $5^{\prime}$ & 129.8 & - & 133.0 & - \\
\hline $6^{\prime}$ & 121.3 & $7.67 \mathrm{~s}$ & 163.2 & $7.33 \mathrm{~s}$ \\
\hline $7^{\prime}$ & 147.2 & - & 163.6 & - \\
\hline $8^{\prime}$ & 130.6 & - & 110.3 & - \\
\hline $9^{\prime}$ & 159.7 & - & 161.1 & - \\
\hline $9^{\prime}-\mathrm{OH}$ & & $12.5 \mathrm{~s}$ & & $12.3 \mathrm{~s}$ \\
\hline $10^{\prime}$ & 112.0 & - & 116.1 & - \\
\hline $11^{\prime}$ & 56.6 & $3.92 \mathrm{~s}$ & 16.4 & $2.16 \mathrm{~d}(\mathrm{~J}=2.0 \mathrm{~Hz})$ \\
\hline $12^{\prime}$ & 20.5 & $2.21 \mathrm{~s}$ & 56.5 & $3.88 \mathrm{~s}$ \\
\hline
\end{tabular}

Abbreviations: $a x$, axial; eq, equatorial.
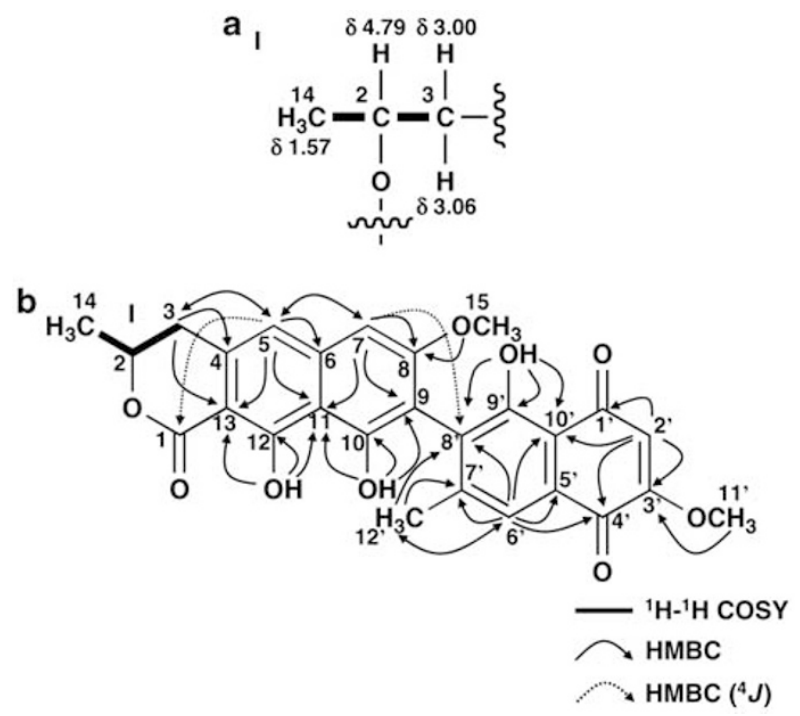

Figure 2 Partial structure (a) and ${ }^{1} \mathrm{H}-{ }^{1} \mathrm{H} \quad \operatorname{COSY}$ and ${ }^{13} \mathrm{C}-{ }^{1} \mathrm{H} \quad \mathrm{HMBC}$ experiments (b) of xanthoradone $A$. 


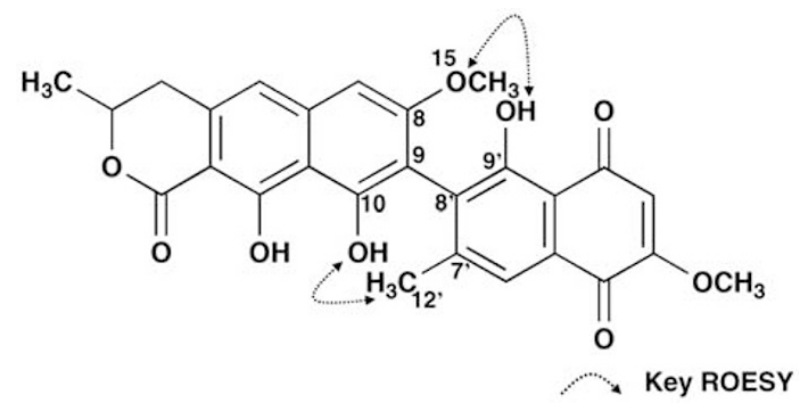

Figure 3 ROESY experiments of xanthoradone A.

rotating frame nuclear overhauser effect spectroscopy (ROESY) experiments (Figure 3), and the long-range coupling of ${ }^{4} J$ observed from $\mathrm{H}-7$ to $\mathrm{C}-8^{\prime}$ in ${ }^{13} \mathrm{C}-{ }^{1} \mathrm{H}$ HMBC experiments (Figure $2 \mathrm{~b}$ ) indicated that the two substructures of dihydronaphthopyranone and naphthoquinone are connected at C-9-C-8'. Taken together, the structure of xanthoradone A was elucidated as shown in Figure 1. The structure satisfied the degree of unsaturation and the molecular formula.

\section{Structure elucidation of xanthoradone $B$}

The molecular formula $\mathrm{C}_{27} \mathrm{H}_{22} \mathrm{O}_{9}$ of xanthoradone $\mathrm{B}$ was the same as that of xanthoradone A. The ${ }^{1} \mathrm{H}$ NMR spectrum of xanthoradone $\mathrm{B}$ was almost identical to that of xanthoradone A except for a weak coupling constant $(J=2.0 \mathrm{~Hz})$ between $\mathrm{H}-2^{\prime}$ and $\mathrm{H}-11^{\prime}$ in xanthoradone $\mathrm{B}$, which was not observed in xanthoradone A. In fact, cross peaks observed from $\mathrm{H}-2^{\prime}\left(\delta\right.$ 6.73) to $\mathrm{C}-4^{\prime}(\delta$ 185.0), C-10' $(\delta 116.1)$ and $\mathrm{C}-11^{\prime}(\delta 16.4)$; from $\mathrm{H}-6^{\prime}(\delta$ 7.33) to C-4', C-5' $(\delta$ 133.0), C-7' $\left(\delta\right.$ 163.6), C-8' $(\delta 110.3)$ and C-10' from OH- $9^{\prime}(\delta 12.3)$ to C-8', C-9' $\left(\delta\right.$ 161.1) and C-10' from $\mathrm{H}_{3}-11^{\prime}(\delta 2.16)$ to $\mathrm{C}-2^{\prime}(\delta 135.8), \mathrm{C}-3^{\prime}$ $\left(\delta\right.$ 148.3) and $\mathrm{C}-4^{\prime}$; and from $\mathrm{H}_{3}-12^{\prime}\left(\delta\right.$ 3.88) to $\mathrm{C}-7^{\prime}$ in the ${ }^{13} \mathrm{C}-{ }^{1} \mathrm{H}$ $\mathrm{HMBC}$ experiments indicated the presence of a naphthoquinone skeleton (Figure 4). This was also supported by the chemical shifts of two carbonyl carbons $\left(\mathrm{C}-1^{\prime}\left(\delta\right.\right.$ 189.0) and C- $\left.4^{\prime}(\delta 185.0)\right)$ derived from a quinone skeleton and the UV absorption $(267 \mathrm{~nm})$. Taken together, the structure of xanthoradone B was elucidated as shown in Figure 1; the oxygenated methyl group at R1 and the methyl group at $\mathrm{R} 2$ in xanthoradone A are reversed in xanthoradone B (Figure 1). The structure satisfied the degree of unsaturation and the molecular formula.

\section{DISCUSSION}

In this study, xanthoradones A and B were isolated from Penicillium radicum strain FKI-3765-2, and their planar structures were elucidated by NMR studies (Figure 1). They were found to have a common asymmetric biaryl skeleton containing a dihydronaphthopyranone and a naphthoquinone. Regarding the stereochemistry of xanthoradones, both xanthoradone $\mathrm{A}$ and $\mathrm{B}$ have one chiral carbon at $\mathrm{C}-2$ in the structure. The orientation of the methyl group at $\mathrm{C}-2$ of the $\delta$-lactone in xanthoradone A was investigated by ${ }^{1} \mathrm{H}-{ }^{1} \mathrm{H}$ spin decoupling experiments. On irradiation at $\mathrm{H}_{3}-14(\delta 1.57)$, a complex multiplet at $\mathrm{H}-2(\delta 4.79)$ became a simple doublet of doublets with $J_{2,3}=10.0$ and $4.0 \mathrm{~Hz}$. The large coupling constant $\left(J_{2,3}=10.0 \mathrm{~Hz}\right)$ indicated that $\mathrm{H}-2$ and $\mathrm{H}_{a x}-3(\delta 3.00)$ are oriented in an axial-axial direction. This was supported by the coupling constants of $\mathrm{H}_{a x}-3$ $(J=17.0,10.0 \mathrm{~Hz})$. Thus, the methyl group at $\mathrm{C}-2$ of the $\delta$-lactone in xanthoradone A was determined to be equatorial in orientation as shown in Figure 1. Similarly, the orientation of the methyl group at $\mathrm{C}-2$ of the $\delta$-lactone in xanthoradone B was also deduced, as shown in Figure 1.

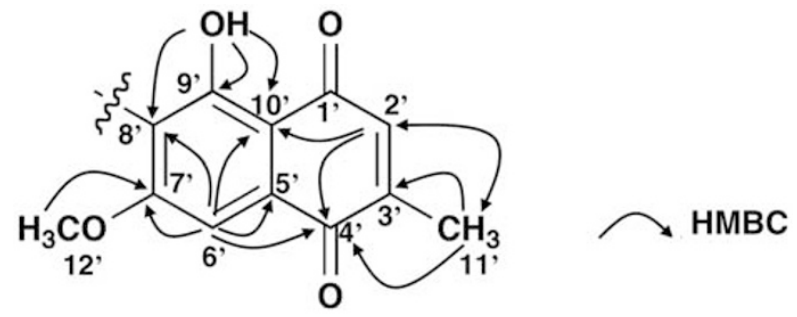

Figure $4{ }^{13} \mathrm{C}-{ }^{1} \mathrm{H}$ HMBC experiments of xanthoradone $\mathrm{B}$.

Some structurally related natural products, such as xanthoviridicatin D produced by Penicillium viridicatum ${ }^{3}$ and xanthoviridicatins E and F, as HIV-1 integrase inhibitors, produced by Penicillium chrysogenum, ${ }^{2}$ have been reported previously (Figure 1). However, the binding pattern of the two substructures differs between xanthoradones and xanthoviridicatins; C-9 of a dihydronaphthopyranone moiety connects with $\mathrm{C}-8^{\prime}$ of the aromatic site of the naphthoquinone moiety in xanthoradones, whereas the former connects with $\mathrm{C}-2^{\prime}$ of the quinone site of the naphthoquinone moiety in known xanthoviridicatins.

By comparison with fungal biaryl compounds containing a dihydronaphthopyranone moiety, such as vioxanthin, ${ }^{4}$ rubrosulphin, ${ }^{5}$ viomellein ${ }^{5}$ and luteosporin, ${ }^{6}$ the absolute configuration of xanthoradones at C-2 can be deduced to be in $2 R$ configuration. Furthermore, xanthoradones $\mathrm{A}$ and $B$ have a chiral axis in the structures. The configuration of the axis might be $M$ by comparing the $\mathrm{CD}$ spectra of $(P)$ and $(M)$-vioxanthins; ${ }^{4}$ xanthoradones show a negative cotton effect at $281-289 \mathrm{~nm}$ and a positive cotton effect at $266-269 \mathrm{~nm}$ similar to $(M)$-vioxanthin.

\section{METHODS}

\section{General experimental procedures}

The UV spectra were recorded on a spectrophotometer (8453 UV-Visible spectrophotometer; Agilent Technologies, Santa Clara, CA, USA). IR spectra were recorded on a Fourier transform infrared spectrometer (FT-710; Horiba, Kyoto, Japan). Optical rotations were measured using a digital polarimeter (DIP-1000; JASCO, Tokyo, Japan). ESI-TOF-MS and HRESI-TOF-MS spectra were recorded on a mass spectrometer (JMS-T100LP; JEOL, Tokyo, Japan). Various NMR spectra were measured using a spectrometer (XL-400; Varian, Palo Alto, CA, USA).

\section{ACKNOWLEDGEMENTS}

This work was supported by a grant-in-aid for Scientific Research (B) 21310146 (to HT) from the Ministry of Education, Culture, Sports, Science and Technology, Japan and the Sasakawa Scientific Research Grant (to HY) from The Japan Science Society. We express our thanks to Ms N Sato for performing NMR experiments, and Dr K Nagai and Ms A Nakagawa for measuring mass spectra.

1 Yamazaki, H., Nonaka, K., Masuma, R., Ōmura, S. \& Tomoda, H. Xanthoradones, new potentiators of imipenem activity against methicillin-resistant Staphylococcus aureus, produced by Penicillium radicum FKI-3765-2 I. Taxonomy, fermentation, isolation and biological properties. J. Antibiot. 62, 431-434 (2009).

2 Singh, S. B. et al. Isolation, structure, and HIV-1 integrase inhibitory activity of xanthoviridicatin $\mathrm{E}$ and $\mathrm{F}$, two novel fungal metabolites produced by Penicillium chrysogenum. Helv. Chim. Acta. 86, 3380-3385 (2003).

3 Stack, M. E., Mazzola, E. P. \& Eppley, R. M. Structure of xanthoviridicatins D and xanthoviridicatin G, metabolites of Penicillium viridicatum: application of proton and carbon-13 NMR spectroscopy. Tetrahedron Lett. 52, 4989-4992 (1979).

4 Bode, S. E., Drochner, D. \& Muller, M. Synthesis, biosynthesis, and absolute configuration of vioxanthin. Angew. Chem. Int. Ed. Engl. 46, 5916-5920 (2007).

5 Durley, R. C., MacMillan, J., Simpson, T. J., Glen, A. T. \& Turner, W. B. Fungal products. Part XIII. Xanthomegnin, viomellin, rubrosulphin, and viopurpurin, pigments from Aspergillus sulphureus and Aspergillus melleus. J. Chem. Soc. Perkin. Trans. 12 , 163-169 (1975).

6 Mori, H., Kawai, K., Ohbayashi, F., Kitamura, J. \& Nozawa, Y. Genotoxicity of quinone pigments from pathogenic fungi. Mutat. Res. 122, 29-34 (1983). 